\title{
Unsur Pelayanan Sesuai Survei Kepuasan Masyarakat (SKM) dengan Kepuasan Peserta Jaminan Kesehatan Nasional di Puskesmas Liya, Wangi- Wangi Selatan Kabupaten Wakatobi
}

\author{
${ }^{1}$ Dyah Fauziah Ilyas, ${ }^{2}$ Asriati, ${ }^{3}$ La Ode Alifariki \\ Program Studi Pendidikan Dokter \\ Fakultas Kedokteran UHO \\ E-mail : adiuskusnan.fkuho@gmail.com; asriatiyusuf@gmail.com; ners_riki@yahoo.co.id
}

Doi: https://doi.org/10.30787/gaster.v18i2.450

Received: July 2019| Revised: July 2019 | Accepted: Agustus 2019

\begin{abstract}
Background: The Community Satisfaction Survey is a comprehensive measurement activity on the level of community satisfaction with the quality of services provided by public service providers. Community Satisfaction Survey Elements are requirements, mechanism and procedure systems, Settlement Time, Cost/Tariff, Product Specifications Type of Service, Competence Executor, Implementing Behavior, facilities and infrastructure, Handling Complaints, Suggestions and Feedback. Research Purpose: to determine the relationship of service elements in accordance with the Community Satisfaction Survey with the satisfaction of national health insurance participants at the Liya Wangi-Wangi Health Center south of Wakatobi Regency. Research Methods: This study used an analytical-observational method with a cross sectional approach. The population of this study were patients who participated in National Health Insurance at the South Liya Wangi-Wangi Health Center in Wakatobi Regency with a population of 600. With a sample of 120 samples taken using accidental sampling method. Data analysis used the Spearman rank correlation test method and was considered significant if $p<0.05$. Research Results: The results of the analysis show that the significant level (sig) is 0,000 (<0.05) which means that there is a significant relationship between the elements of service to patient satisfaction the amount of the Spearman Rank correlation coefficient is 0.681. Conclusion: The conclusion of this study, there is a relationship between the elements of service and satisfaction of participants of the National Health Insurance at the Liya Wangi-Wangi Selatan Health Center in Wakatobi Regency.
\end{abstract}

Keywords: Satisfaction; health service elements; SKM; JKN

\section{PENDAHULUAN}

Pengguna jasa pelayanan kesehatan di Puskesmas menuntut pelayanan yang berkualitas tidak hanya menyangkut kesembuhan dari penyakit secara fisik akan tetapi juga menyangkut kepuasan terhadap sikap, pengetahuan dan keterampilan petugas dalam memberikan pelayanan serta tersedianya sarana dan prasarana yang memadai dan dapat memberikan 
kenyamanan. Dengan semakin meningkatnya kualitas pelayanan maka fungsi pelayanan di Puskesmas perlu ditingkatkan agar menjadi lebih efektif dan efisien serta memberikan kepuasan terhadap pasien dan masyarakat.

Berdasarkan BPJS Kesehatan jumlah pengguna terhitung sampai dengan 23 September 2016 sebesar 169.304.759 juta orang. BPJS Kesehatan sebagai penyelenggara melakukan koordinasi dengan fasilitas kesehatan untuk mendukung program JKN-KIS agar dapat memberikan pelayanan kesehatan secara merata kepada masyarakat (Putri dan Kartika, 2017).

Data BPJS kesehatan di Kabupaten Wakatobi jumlah penduduk sebanyak 110.303 dan jumlah pasien pengguna Jaminan Kesehatan Nasional (JKN) yang terdaftar pada tahun 2018 sebanyak 83.756 jiwa atau 75,9\%. (BPJS Kesehatan, 2018).

Berdasarkan data Puskesmas Liya pada tahun 2016 menunjukan bahwa jumlah peserta JKN sebesar 3.325 jiwa atau $76,6 \%$ dan yang tidak memiliki JKN sebesar 1.018 jiwa atau 23,4\%. Hal tersebut menunjukkan bahwa sebagian besar penduduk di Puskesmas Liya telah memiliki Jaminan Kesehatan. (Profil Puskesmas Liya, 2016).

Untuk Tahun 2017 di dapatkan peserta JKN sebanyak 3640 jiwa atau 83,8\% dan
2018 penggunaan JKN meningkat yaitu 4042 jiwa atau 93\%. Dan setiap bulannya untuk kunjungan sakit dan kunjungan sehat sekitar 15\% yaitu sebanyak 600 jiwa. (Laporan Bulanan Puskesmas Liya, 2018).

Penelitian yang dilakukan oleh Indriyatni (2011), dan Astuti (2018) menunjukkan bahwa kualitas pelayanan pada dimensi bukti langsung, kehandalan, daya tanggap, jaminan, dan empati terbukti berpengaruh signifikan terhadap kepuasan pasien.

Hasil penelitian Istanto dan Niswah (2016) mendapatkan nilai $81,7 \%$ atau sangat puas pada keseluruhan pelayanan yang dinilai berdasarkan 8 indikator yang terdapat di dalam Keputusan Menteri Pendayagunaan Aparatur Negara dan Reformasi Birokrasi, antara lain: persyaratan, prosedur pelayanan, waktu pelayanan, produk spesifikasi jenis pelayanan, kompetensi pelaksana, perilaku pelaksana, maklumat pelayanan, serta penanganan pengaduan, saran, dan masukan. Penelitian ini menggunakan sampel sebanyak 97 orang, dengan jumlah populasi sebanyak 3360 orang.

\section{METODE DAN BAHAN}

Penelitian ini merupakan penelitian analitik observasional dengan metode cross sectional. Penelitian ini dilaksanakan pada bulan Desember 2018, di Puskesmas Liya 
Wangi-Wangi Selatan Kab. Wakatobi. Tekhnik pengambilan sampel pada penelitian ini menggunakan tekhnik Nonprobability Sampling yaitu accidental sampling dengan total sampel sebanyak 120 pasien.

Pengumpulan data primer dilakukan melalui wawancara dengan responden menggunakan instrument penelitian berupa kuesioner dengan menggunakan skala Likert. Analisis data dengan menggunakan uji Korelasi Rank Spearman karena termaksud nonparametrik test yang terdiri dari satu variabel bebas (unsur pelayanan) dan satu variabel terikat (kepuasan pasien) yang memiliki skala ordinal.

\section{HASIL DAN PEMBAHASAN}

\section{Analisis Univariat}

Tabel 1. Distribusi Responden Berdasarkan Jenis Kelamin, Kelompok Umur dan Status Pekerjaan di Puskesmas Liya Kab. Wakatobi

\begin{tabular}{lcc}
\hline Jenis Kelamin & Frekuensi & $\begin{array}{c}\text { Presentase } \\
(\%)\end{array}$ \\
\hline Laki-laki & 32 & 26.7 \\
Perempuan & 88 & 73.3 \\
Kelompok Umur & & \\
14-21 tahun & 7 & 5.8 \\
22-29 tahun & 20 & 16.7 \\
30-37 tahun & 23 & 19.2 \\
& & \\
\hline
\end{tabular}

\begin{tabular}{lcc}
\hline $38-45$ tahun & 20 & 16.7 \\
46-53 tahun & 35 & 29.2 \\
54-61 tahun & 15 & 12.5 \\
Status Pekerjaan & & \\
Bekerja: & & \\
Pegawai Swasta & 8 & 6.7 \\
Pegawai Negeri & 12 & 10.0 \\
Wiraswasta & 27 & 22.5 \\
Nelayan & 20 & 16.7 \\
Petani & 4 & 3.3 \\
Tidak Bekerja: & & \\
IRT & 42 & 35.0 \\
Pelajar/Mahasiswa & 7 & 5.8 \\
\hline
\end{tabular}

Sumber: Data Primer

Berdasarkan tabel 1 diketahui dari 120 responden pasien rawatjalan pesertaJKNyang diteliti didapatkan paien laki-laki sebnayak 32 (26,7\%) responden dan perempuan sebanyak $88(73.3 \%)$ responden. Responden menurut kelompok umur. Sebagian besar responden didominasi oleh kelompok umur 46-53 tahun yaitu sejumlah 35 (29.2\%) responden sedangkan untuk kelompok umur 30-37 tahun yaitu sejumlah 23 (19.2\%) responden, untuk kelompok umur 38-45 tahun yaitu sejumlah $20(16.7 \%)$ responden, untuk kelompok umur 22-29 tahun yaitu sejumlah 20 (16.7\%) responden, dan untuk kelompok umur 54-61 tahun yaitu sejumlah 15 (12.5\%) responden, sedangkan kelompok umur 14-21 sangat sedikit jumlahnya yaitu sejumlah 7 (5.8\%) responden. 
Tabel 2. Distribusi Frekuensi Unsur Pelayanan Persyaratan dengan kepuasan di Puskesmas Liya

\begin{tabular}{lcc}
\hline Persyaratan & Frekuensi & Presentase (\%) \\
\hline Puas & 120 & 100 \\
Tidak Puas & 0 & 0.0 \\
Total & $\mathbf{1 2 0}$ & $\mathbf{1 0 0 \%}$ \\
\hline
\end{tabular}

Sumber: Data Primer

Berdasarkan tabel 2. diketahui bahwa dari 120 responden, menunjukkan responden yang menyatakan puas terhadap unsur pelayanan persyaratan di Puskesmas Liya Kabupaten Wakatobi yaitu sebanyak 120 (100\%) orang dan yang menyatakan tidak puas tidak ada $(0.0 \%)$

Tabel 3. Distribusi Frekuensi Unsur Pelayanan Sistem, Mekanisme dan Prosedur dengan kepuasan di Puskesmas Liya Kab.Wakatobi.

\begin{tabular}{lcc}
\hline $\begin{array}{l}\text { Sistem, } \\
\text { Mekanisme } \\
\text { dan Prosedur }\end{array}$ & Frekuensi & Presentase (\%) \\
\hline Puas & 120 & 100 \\
Tidak Puas & 0 & 0.0 \\
Total & $\mathbf{1 2 0}$ & $\mathbf{1 0 0 \%}$ \\
\hline
\end{tabular}

Sumber: Data Primer

Berdasarkan tabel 3. diketahui bahwa dari 120 responden, menunjukkan responden yang menyatakan puas terhadap unsur pelayanan sistem mekanisme dan prosedur di Puskesmas Liya Kabupen Wakatobi yaitu $120(100 \%)$ orang dan yang menyatakan tidak puas tidak ada (0.0).

Unsur prosedur pelayanan sudah baik di Puskesmas Liya Kabupaten Wakatobi . Hal tersebut menandakan penilaian masyarakat yang telah mendapatkan pelayanan kesehatan di Puskesmas Liya Kabupaten Wakatobi melalui kuisioner yang telah disebarkan ketika peneliti melakukan penggalian data di lapangan, masyarakat mendapat kejelasan dalam prosedur layanan di puskesmas dan telah dilayani oleh petugas kesehatan dengan baik. Prosedur untuk mendapatkan pelayanan dengan mudah yaitu masyarakat hanya perlu datang ke Puskesmas Liya dan mengantri untuk mendapatkan pelayanan dari petugas kesehatan, kemudian setelah dilayani dan melengkapi persyaratan, berkas akan diproses di bagian administrasi Puskesmas Liya hingga selesai.

Setelah itu pasien akan diarahkan menuju bagian pemeriksaan kesehatan dan di tangani oleh petugas kesehatan setelah itu pergi ke bagian apoteker untuk mengambil obat. Oleh karena itu, unsur prosedur pelayanan kesehatan di Puskesmas Liya Kabupaten Wakatobi dinyatakan memuaskan. 
Tabel 4. Distribusi Frekuensi Unsur Pelayanan Waktu Penyelesaian dengan kepuasan di Puskesmas Liya Kab. Wakatobi.

\begin{tabular}{lcc}
\hline $\begin{array}{l}\text { Waktu } \\
\text { Penyelesaian }\end{array}$ & Frekuensi & Presentase (\%) \\
\hline Puas & 120 & 100 \\
Tidak Puas & 0 & 0.0 \\
Total & $\mathbf{1 2 0}$ & $\mathbf{1 0 0 \%}$ \\
\hline
\end{tabular}

Sumber: Data Primer

Berdasarkan tabel 4. diketahui bahwa dari 120 responden, menunjukkan responden yang menyatakan puas terhadap unsur pelayanan waktu penyelesaian di Puskesmas Liya Kabupaten Wakatobi yaitu 120 (100\%) orang dan yang menyatakan tidak puas tidak ada $(0.0 \%)$. Unsur waktu pelayanan sudah baik di Puskesmas Liya Kabupaten Wakatobi. Hal tersebut menandakan penilaian masyarakat yang telah mendapatkan pelayanan kesehatan di Puskesmas Liya Kabupaten Wakatobi melalui kuisioner yang telah disebarkan ketika peneliti melakukan penggalian data di lapangan.

Masyarakat mendapat prosedur penerimaan pasien yang dilakukan dengan ramah dan dengan alur pelayanan sesuai prosedur standar operasional, sehingga pasien tidak perlu menunggu lama untuk mendapat pelayanan waktu pelayanan dengan cepat. Oleh karena itu, unsur waktu pelayanan kesehatan di Puskesmas Liya Kabupaten Wakatobi dinyatakan memuaskan.
Tabel 5. Distribusi Frekuensi Unsur Pelayanan Biaya/tariff dengan kepuasan di Puskesmas Liya Kab.Wakatobi.

\begin{tabular}{lcc}
\hline Biaya/tarif & Frekuensi & Presentase (\%) \\
\hline Puas & 120 & 100 \\
Tidak Puas & 0 & 0.0 \\
Total & $\mathbf{1 2 0}$ & $\mathbf{1 0 0 \%}$ \\
\hline
\end{tabular}

Sumber: Data Primer

Berdasarkan tabel 5. diketahui bahwa dari 120 responden, menunjukkan responden yang menyatakan puas terhadap unsur pelayanan biaya/tariff di Puskesmas Liya Kabupaten Wakatobi yaitu 120 (100\%) orang dan yang menyatakan tidak puas tidak baik $(0.0 \%)$. Unsur biaya/tarif pelayanan sudah. baik di Puskesmas Liya Kabupaten Wakatobi Hal tersebut menandakan penilaian masyarakat yang telah mendapatkan pelayanan kesehatan di Puskesmas Liya Kabupaten Wakatobi melalui kuisioner yang telah disebarkan ketika peneliti melakukan penggalian data di lapangan.

Peranan BPJS dalam mengendalikan biaya pelayanan kesehatan menjadi pemicu utama dalam meningkatkan kepuasan masyarakat terhadap unsur pembiayaan/tarif. Hal ini disebabkan oleh seluruh pasien peserta BPJS mendapatkan pelayanan kesehatan secara gratis di Puskesmas Liya Kabupaten Wakatobi. 
Tabel 6. Distribusi Frekuensi Unsur Pelayanan Produk Spesifikasi Jenis Pelayanan dengan kepuasan di Puskesmas Liya Kab. Wakatobi.

\begin{tabular}{lcc}
\hline $\begin{array}{l}\text { Produk } \\
\text { Spesifikasi } \\
\text { Jenis Pelayanan }\end{array}$ & Frekuensi & $\begin{array}{c}\text { Presentase } \\
(\%)\end{array}$ \\
\hline Puas & 120 & 100 \\
Tidak Puas & 0 & 0.0 \\
Total & $\mathbf{1 2 0}$ & $\mathbf{1 0 0 \%}$ \\
\hline
\end{tabular}

Sumber: Data Primer

Berdasarkan tabel 6 diketahui bahwa dari 120 responden, menunjukkan responden yang menyatakan puas terhadap unsur pelayanan produk spesifikasi jenis layanan di Puskesmas Liya Kabupaten Wakatobi yaitu 120 (100\%) orang dan yang menyatakan tidak puas tidak ada $(0.0 \%)$

Unsur Produk spesifikasi jenis pelayanan sudah baik di Puskesmas Liya Kabupaten Wakatobi. Hal tersebut menandakan penilaian masyarakat yang telah mendapatkan pelayanan kesehatan di Puskesmas Liya Kabupaten Wakatobi melalui kuisioner yang telah disebarkan ketika peneliti melakukan penggalian data di lapangan.

Masyarakat mendapat kejelasan tentang produk spesifikasi jenis pelayanan, dan telah dilayani oleh petugas dengan baik sudah sesuai dengan jenis pelayanannya.
Oleh karena itu, Unsur Pelayanan produk spesifikasi jenis pelayanan kesehatan di Puskesmas Liya Kabupaten Wakatobi di nyatakan memuaskan.

Tabel 7. Distribusi Frekuensi Unsur Pelayanan Kompetensi pelaksana dengan kepuasan di Puskemas Liya Kab.Wakatobi

\begin{tabular}{lcc}
\hline $\begin{array}{l}\text { Kompetensi } \\
\text { pelaksana }\end{array}$ & Frekuensi & Presentase (\%) \\
\hline Puas & 120 & 100 \\
Tidak Puas & 0 & 0.0 \\
Total & $\mathbf{1 2 0}$ & $\mathbf{1 0 0 \%}$ \\
\hline
\end{tabular}

Sumber: Data Primer

Berdasarkan tabel 7 diketahui bahwa dari 120 responden, menunjukkan responden yang menyatakan puas terhadap unsur pelayanan Kompetensi pelaksana di Puskesmas Liya Kabupaten Wakatobi yaitu $120 \quad(100 \%)$ orang dan yang menyatakan tidak puas tidak ada $(0.0 \%)$. Unsur kompetensi pelaksana pelayanan sudah baik di Puskesmas Liya Kabupaten Wakatobi. Hal tersebut menandakan penilaian masyarakat yang telah mendapatkan Pelayanan kesehatan di Puskesmas Liya Kabupaten Wakatobi melalui kuisioner yang telah disebarkan ketika peneliti melakukan penggalian data di lapangan, masyarakat mendapat layanan oleh petugas kesehatan dengan baik. 
Kompetensi petugas kesehatan dalam memberikan pelayanan sudah sesuai dengan prosedur standar operasional yaitu dari melalukan tanya jawab antar petugas kesehatan dan pasien, melakukan pemeriksaan fisik dan menangani penyakit pasien dengan baik juga dipengaruhi oleh tingkat pendidikan petugas kesehatan. Selain itu keahlian dan ketrampilan petugas yang baik disebabkan karena setiap petugas kesehatan memahami seluruh pelayanan yang ada. Oleh karena itu, Unsur kompetensi pelaksana di Puskesmas Liya Kabupaten Wakatobi dinyatakan memuaskan.

Tabel 8. Distribusi Frekuensi Unsur Pelayanan Perilaku Pelaksana dengan kepuasan di Puskesmas Liya Kab. Wakatobi.

\begin{tabular}{lcc}
\hline $\begin{array}{l}\text { Perilaku } \\
\text { Pelaksana }\end{array}$ & Frekuensi & $\begin{array}{c}\text { Presentase } \\
(\%)\end{array}$ \\
\hline Puas & 120 & 100 \\
Tidak Puas & 0 & 0.0 \\
Total & $\mathbf{1 2 0}$ & $\mathbf{1 0 0 \%}$ \\
\hline
\end{tabular}

Sumber: Data Prime

Berdasarkan tabel 8 diketahui bahwa dari 120 responden, menunjukkan responden yang menyatakan puas terhadap unsur pelayanan Perilaku Pelaksana di Puskesmas Liya Kabupaten Wakatobi yaitu 120 (100\%) orang dan yang menyatakan tidak puas tidak ada $(0.0 \%)$.
Unsur perilaku pelaksana pelayanan sudah baik di Puskesmas Liya Kabupaten. Hal tersebut menandakan penilaian masyarakat yang telah mendapatkan pelayanan kesehatan di Puskesmas Liya Kabupaten wakatobi melalui kuisioner yang telah disebarkan ketika peneliti melakukan penggalian data di lapangan, peneliti mendapatkan bahwa pelayanan yang diberikan petugas kesehatan sudah baik kepada pasien. Perilaku yang baik ini ditunjukkan petugas melalui perilaku yang sopan terhadap pasien, daya tanggap yang baik, ramah serta tidak membeda-bedakan dalam memberikan pelayanan Oleh karena itu, Unsur perilaku pelaksana pelayanan kesehatan di Puskesmas Liya Kabupaten Wakatobi dinyatakan memuaskan.

Tabel 9. Distribusi Frekuensi Unsur Pelayanan Sarana dan prasarana dengan kepuasan di Puskesmas Liya Kab. Wakatobi.

\begin{tabular}{lcc}
\hline $\begin{array}{l}\text { Sarana dan } \\
\text { Prasarana }\end{array}$ & Frekuensi & $\begin{array}{c}\text { Presentase } \\
(\%)\end{array}$ \\
\hline Puas & 99 & 82.5 \\
Tidak puas & 21 & 17.5 \\
Total & $\mathbf{1 2 0}$ & $\mathbf{1 0 0 \%}$ \\
\hline
\end{tabular}

Sumber: Data Primer

Berdasarkan tabel 9 diketahui bahwa dari 120 responden, menunjukkan responden yang menyatakan puas terhadap unsur pelayanan Sarana dan Prasarana di Puskesmas Liya 
Kabupaten Wakatobi yaitu 99 (82.5\%) orang. Dan yang menyatakan tidak puas $21(17,5 \%)$ orang.

Tabel 10. Distribusi Frekuensi Unsur Pelayanan Penanganan Pengaduan Saran dengan kepuasan di Puskesmas Liya Kab. Wakatobi.

\begin{tabular}{lcc}
\hline $\begin{array}{l}\text { Penanganan } \\
\text { Pengaduan } \\
\text { Saran dan } \\
\text { Masukan }\end{array}$ & Frekuensi & Presentase (\%) \\
\hline Puas & 120 & 100.0 \\
Tidak Puas & 0 & 0.0 \\
Total & $\mathbf{1 2 0}$ & $\mathbf{1 0 0 \%}$ \\
\hline
\end{tabular}

Sumber: Data Primer

Berdasarkan tabel 10. diketahui bahwa dari 120 responden, menunjukkan responden yang menyatakan puas terhadap unsur pelayanan Penanganan Pengaduan Saran dan Masukan di Puskesmas Liya Kabupaten Wakatobi yaitu 120 (100\%) orang dan yang menyatakan tidak puas tidak ada $(0.0 \%)$.

Unsur penanganan pengaduan saran dan masukan pelayanan sudah baik di Puskesmas Liya Kabupaten Wakatobi. Hal tersebut menandakan penilaian masyarakat yang telah mendapatkan pelayanan kesehatan di puskesmas Liya Kabupaten Wakatobi melalui kuisioner yang telah disebarkan ketika peneliti melakukan penggalian data di lapangan, masyarakat mendapat keterbukaan tentang penanganan pengaduan saran dan masukan pelayanan dari pelaksana pelayanan dengan perilaku yang baik.

Dan pengaduan dari masyarakat biasanya dengan menggunakan nomor telepon dari puskesmas itu sendiri. Oleh karena itu, unsur penanganan pengaduan saran dan masukan di Puskesmas Liya Kabupaten Wakatobi dinyatakan memuaskan.

Penelitian ini sejalan dengan yang di lakukan oleh Badan POM (2018) tentang Laporan Survei Kepuasan Masyarakat Tahun 2018. Hasil penilaian survei kepuasan masyarakat dengan 1.796 responden pada 13 unit kerja di lingkungan Badan POM pusat tahun 2018 menghasilkan nilai survei kepuasan masyarakat (SKM) terhadap penyelenggaraan pelayanan publik sebesar 81,32. Dengan demikian berdasarkan nilai tersebut dapat disimpulkan bahwa secara keseluruhan mutu pelayanan Badan POM Pusat mendapatkan kategori B yaitu persepsi kinerja unit pelayanan Baik

Tabel 11. Unsur Pelayanan sesuai Survei Kepuasan Masyarakat.

\begin{tabular}{llcc}
\hline Unsur Pelayanan & $\begin{array}{c}\text { NRR } \\
\text { per } \\
\text { Unsur }\end{array}$ & $\begin{array}{c}\text { NRR } \\
\text { tertimbang } \\
\text { per unsur }\end{array}$ \\
\hline 1 & $\begin{array}{l}\text { Persyaratan } \\
\text { Pelayanan }\end{array}$ & 3.13 & 0.34 \\
2 & $\begin{array}{l}\text { Prosedur Pelayanan } \\
3\end{array}$ & 3.52 & 0.38 \\
Waktu Pelayanan & 3.48 & 0.38 \\
\hline
\end{tabular}




\begin{tabular}{llcc}
\hline Unsur Pelayanan & $\begin{array}{c}\text { NRR } \\
\text { per } \\
\text { Unsur }\end{array}$ & $\begin{array}{c}\text { NRR } \\
\text { tertimbang } \\
\text { per unsur }\end{array}$ \\
\hline 4 & Biaya/Tariff & 4 & 0.44 \\
5 & $\begin{array}{l}\text { Produk Spesifikasi } \\
\text { Jenis Layanan }\end{array}$ & 3.62 & 0.39 \\
6 & $\begin{array}{l}\text { Kompetensi } \\
\text { Pelaksana }\end{array}$ & 3.43 & 0.37 \\
7 & $\begin{array}{l}\text { Perilaku Pelaksana } \\
8\end{array}$ & 3.68 & 0.40 \\
$\begin{array}{l}\text { Sarana dan } \\
\text { Prasarana } \\
9\end{array}$ & 3.35 & 0.36 \\
& $\begin{array}{l}\text { Penanganan } \\
\text { Pengaduan }\end{array}$ & 3.36 & 0.36 \\
\hline & & 3.47 \\
\hline & Nilai Indek (NI) & & 86.80 \\
\hline & Kilai SKM di & & \\
\hline
\end{tabular}

Sumber: Data Primer
Maka untuk mengetahui nilai survei unit pelayanan dihitung dengan cara sebagai berikut: $(3.13 \times 0.111)+(3.52 \times 0.111)+$ $(3.48 \times 0.111)+(4 \times 0.111)+(3.62 \times 0.111)$ $+(3.43 \mathrm{x} 0.111)+(3.68 \times 0.111)+(3.35 \mathrm{x}$ $0.111)+(3.36 \times 0.111)=3.47$

Nilai survei adalah 3.47. Dengan demikian, nilai Survei Kepuasan Masyarakat unit pelayanan hasilnya dapat disimpulkan sebagai berikut:

a. Nilai SKM setelah dikonversi

$=$ Nilai Survei x Nilai Dasar

$=3.47 \times 25=86.80$

b. Mutu pelayanan B

c. Kinerja unit pelayanan Memuaskan

\section{Analisis Bivariat}

Tabel 12 Uji Korelasi Unsur Pelayanan Sarana dan Prasarana dengan Kepuasan Pasien di Puskesmas Liya Kab. Wakatobi

\begin{tabular}{lccccccc}
\hline \multirow{2}{*}{$\begin{array}{l}\text { Sarana dan } \\
\text { Prasarana }\end{array}$} & \multicolumn{3}{c}{ Kepuasan Pasien } & Total & $\mathrm{r}_{\mathrm{s}}$ & p-value \\
\cline { 2 - 5 } & $\mathrm{n}$ & $\%$ & $\mathrm{n}$ & $\%$ & & & \\
\cline { 2 - 5 } Sangat Baik & 63 & 98,4 & 1 & 1,6 & 64 & & \\
Baik & 36 & 100,0 & 0 & 0,0 & 36 & 0,681 & 0,000 \\
Kurang Baik & 0 & 0,0 & 20 & 100.0 & 20 & & \\
\hline Total & 99 & 82,5 & 21 & 17,5 & 120 & & \\
\hline
\end{tabular}

Sumber: Data Primer

Berdasarkan tabel 12, dapat diketahui bahwa pada Unsur Pelayanan Sarana dan Prasarana kelompok yang menyatakan puas dengan unsur pelayanan yang sangat baik diperoleh 63 sampel (98.4\%), sedangkan yang menyatakan tidak puas dengan unsur pelayanan yang sangat baik diperoleh 1 sampel (1.6\%). 
Pada kelompok yang menyatakan puas dengan unsur pelayanan yang baik diperoleh 36 sampel (100,0\%), sedangkan pada kelompok yang menyatakan tidak puas dengan unsur pelayanan yang baik sebanyak 0 sampel (0.0\%), dan yang menyatakan puas dengan unsur pelayanan kurang baik $0(0.0 \%)$ dan yang menyatakan tidak puas dengan unsur pelayanan kurang baik 20 (100.0\%).

Berdasarkan hasil analisis diatas menunjukkan bahwa besarnya koefisien korelasi Rank Spearman antara unsur pelayanan sarana dan prasarana dengan kepuasan pasien adalah sebesar 0,681 dan angka tingkat signifikan (sig) sebesar 0,000 $(<0,05)$. Berdasarkan hasil uji statistik menunjukkan bahwa pada unsur pelayanan sarana dan prasarana terhadap kepuasan pasien yang didapatkan nilai $\mathrm{p}$ yaitu 0,000 $(p<0,05)$. Hasil ini menunjukkan bahwa ada hubungan yang signifikan antara Unsur Pelayanan terhadap kepuasan pasien sehingga $\mathrm{H}_{0}$ ditolak dan $\mathrm{H}_{\mathrm{a}}$ diterima. Pada hasil olahan data itu pula di dapatkan $r_{s}$ 0,681 yang berarti hubungan unsur pelayanan dengan kepuasan pasien sangat kuat.

Untuk melihat arah hubungan antara dua variabel tersebut dilihat dari apakah nilai koefisien korelasi bernilai positif atau negatif karena nilainya positif, maka dapat diketahui bahwa unsur pelayanan kesehatan berbanding lurus/searah dengan kepuasan pasien
Sarana dan prasarana merupakan instrumen pendukung dalam memberikan pelayanan kesehatan yang maksimal. Hal ini menjadi salah satu faktor dalam menentukan tingkat kepuasan pasien terhadap pelayanan kesehatan di puskesmas. Hasil observasi yang dilakukan peneliti menunjukan bahwa 99 sampel (82,5\%) menyatakan puas dengan sarana dan prasarana yang baik. Hal ini menunjukan bahwa sebagian besar masyarakat sudah puas dengan sarana dan prasarana yang ada di Puskesmas Liya Kabupaten Wakatobi. Sampel yang menyatakan tidak puas dengan sarana dan prasarana yang kurang baik terdapat 21 sampel $(17,5 \%)$.

Hasil ini menjelaskan bahwa sebagian kecil masyarakat tidak puas menganggap beberapa sarana dan prasarana kurang baik seperti lahan parkir yang sempit dan tidak strategis serta peralatan medis seperti pemeriksaan penunjang yang kurang memadai.

Kondisi bangunan dan prasarana yang ada secara umum dapat dikategorikan baik, karena semua berfungsi dengan baik. Namun sebagian sarana dan prasarana diantaranya ruang pemeriksaan dirasakan kurang nyaman digunakan karena terlalu sempit, kelengkapan obat serta pemeriksaan penunjang yang dibutuhkan dalam mendiagnosa pasien dinilai masih kurang. 
Selain itu tempat parkir yang sempit dan dinilai tidak strategis karena terletak di depan area gedung. Mobil ambulance, pasien yang membawa kendaraan bermotor dan pegawai puskesmas yang membawa kendaraan bermotor merasakan ketidaknyamanan akan kebutuhan tempat parkir.

\section{DAFTAR PUSTAKA}

Antaranews Sultra. 2017. 71,09 Persen Penduduk Sultra Peserta BPJS Kesehatan. https://sultra. antaranews.com/berita/291155/7109-persen-penduduk-sultra-peserta-bpjs-kesehatan.

Astuti, Resti. 2018. Hubungan Kualitas Pelayanan Terhadap Kepuasan Pasien Pengguna Jaminan Kesehatan Nasional di BLUD Rumah Sakit Konawe Selatan. Skripsi. Fakultas Kedokteran Universitas Halu Oleo. Kendari.

Badan POM. 2018. Laporan Survei Kepuasan Masyarakat Tahun 2018. Badan Pengawas Obat dan Makanan. Jakarta

CNN Indonesia. 2018. Tahun Baru, 69,8 Juta Orang Belum Terdaftar BPJS Kesehatan. https:// www.cnnindonesia.com/ekonomi/20180102124635-78-266076/tahun-baru-698-jutaorang-belum-terdaftar-bpjs-kesehatan.

Dewi, T. N. 2018. Pertemuan Forum Kemitraan dan Komunikasi Tingkat Kabupaten Wakatobi. BPJS Kesehatan. Wakatobi.

Etildawati, Handayani, D. Y. 2017. Hubungan Kualitas Mutu Pelayanan Kesehatan Dengan Kepuasan Pasien Peserta Jaminan Kesehatan Nasional. Universitas Muhammadiyah Purwokerto. Jawa Tengah.

Istanto, E.D dan Niswah, F. 2016. Survei Kepuasan Masyarakat pada Program Kartu Keluarga Data Ulang (KAKEKKU DATANG) di Dinas Kependudukan dan Pencatatan Sipil Kabupaten Gresik. Administrasi Negara, FISH, UNESA.

Indriyatni,Lies. 2011. Analisis Kualitas Jasa PelayananTerhadap Kepuasan Pasien. RSU. Ungaran di Kabupaten Semarang . Jurnal STIE Semarang. Vol. 3, No. 2, Hal 1-14, Edisi Juni 2011. 
ISSN 1858-3385, E-ISSN 2549-7006

GASTER Vol. 18 No. 2, Agustus 2020

Putri, BS., Kartika, L. 2017. Pengaruh Kualitas Pelayanan BPJS Kesehatan Terhadap Kepuasan Pengguna Perspektif Dokter Rumah Sakit Hermina Bogor. Jurnal Riset Manajemen dan Bisnis 2 (1): 1 - 12

Puskesmas Liya Wangi-Wangi Selatan. 2016. Profil Puskesmas Liya Wangi-Wangi Selatan. Wangi-Wangi. Wakatobi

Puskesmas Liya Wangi-Wangi Selatan. 2018. Laporan Bulanan Puskesmas Liya Wangi-Wangi Selatan . Wangi-Wangi. Wakatobi

Peraturan Menteri Pendayagunaan dan Aparatur Negara Nomor 14 Tahun 2017 tentang Pedoman Penyusunan Survei Kepuasan Masyarakat Unit Penyelenggara Pelayanan Publik. Menpan. RI 